\title{
Sociodemographic Structures and Processes Predispose Caribbean Populations to Risk and Social Vulnerability
}

\author{
Valentine Smith \\ Cipriani College of Labour and Cooperative Studies, Trinidad and Tobago
}

\begin{abstract}
In order to understand the population dynamics and the accompanying socio-demographic variables' trends, risks, and social vulnerability, one must have an understanding of the history and contemporary nature of the political economy of the region. The colonization of the Caribbean depended on the exploitation of suitable and abundant workforce to man the plantations which supplied the raw material manufactured from the lucrative mono-crop (sugar cane). Exploitation refers to the appropriation of the surplus of production over and above what the producers needed to reproduce and re-energize their bodies, so as to sustain their lives and the labour process. The traditional social system was emasculated with inequities which impacted mostly on the rapidly increasing population. The movement for independence sought political power so as to use the State as the lever to redress the inequities and to promote the social and economic development of the region. The assumption was that economic development would improve the material conditions of life for the majority of the people, mainly African and East Indians, thereby provide the basis for the social development of the societies of the region. The study has identified the impact the "brain drain" is having in some areas of economic development and at the same time, the important role Caribbean governments have to play in the formulation of education policies that will benefit the most vulnerable groups in Caribbean societies so that they can be able to improve their social and psychological living standards.
\end{abstract}

Keywords: Anglophone Caribbean, political economy, population, social vulnerability, political economy

\section{Introduction}

In order to understand the population dynamics and the accompanying socio-demographic variables' trends, risks and social vulnerability, the reader of this essay must have an understanding of the historical and contemporary nature of the political economy of the region. The Caribbean is defined by a common history of the exploitation of labour of slaves and indentured servants in the production of primary agricultural and mineral products for export to the markets of Europe. Exploitation refers to the appropriation of the surplus of production over and above what the producers needed to reproduce and re-energize their bodies, so as to sustain their lives and the labour process. The traditional social system was emasculated with inequities which impacted mostly on the rapidly increasing population. Yet, free village settlements emerged throughout the Anglophone Caribbean, communities in which a newly freed people began to adjust to a new beginning from the past distorted by slavery (Mintz 1974).

The phenomenon of "highland adaptation" coined by Sidney Mintz (1974) is an attempt by him to capture the ecological essence of these new settlements that are still evident today in most Caribbean societies. As you leave the sea-ports of the Anglophone Caribbean countries, you can observe the thousands of hillside houses that are associated with the history of the decade after slavery and which is connected to a distinctive environmental dimension that is still evident today.

The movement for independence sought political power so as to use the State as the lever to redress the inequities and to promote the social and economic development of the region. The assumption was that economic development would improve the material conditions of life for the majority of the people, mainly African and East Indians, and thereby provide the basis for the social development of the societies of the region. In its widest interpretation, the movement for independence began with the Haitian revolution, proceeded by way of rebellion, peaceful resistance, and even accommodation, through the Cuban revolution, and culminated in the constitutional decolonization of the Anglophone Caribbean. While remnants of the independence movement persist in these modern colonies, by and large, there appears to be a resignation to the colonial status because of the welfare payments that sustain the majority of the people, as well as the negative 
demonstration effect of the economic failures in those countries which won formal political independence.

Today, there appears to be a reversal of this process, as a new form of colonialism is being rapidly established through the aegis of the multilateral lending institutions. The essence of this new form of colonialism is the transfer of surplus through debt and the flight of capital, in addition to the historical forms of profit repatriation, and unequal exchange in international markets. The State has become the primary mechanism for the transfer of the surplus through debt payments. Instead of being a mechanism under popular control for promoting economic development of a type that benefits the majority of the people and for addressing the social inequalities, it has become more efficient in taxing the ordinary people, more capable of repression, and has made a virtue out of promoting a type of economic development based on cheap labour, and hence low incomes for the producers, and oriented to the satisfaction of foreign demand. In terms of taxation, the regional trend is towards value-added taxes on consumption, which appears to become democratic, but is regressive against the lowest income groups in the society.

An integral part of the new strategy for economic development is the relinquishing of responsibility of the regulation of market and other forms of economic activity, and the provision of social services. Deregulation really means that the State ceases to regulate the market and other forms of economic activity. In really the market continues to be regulated, but by those social forces with the requisite economic power, and to their own benefit. Social services are left to market forces, which means that those without income to access the relevant markets have to do without the benefits of the services. The well known justification for the divestment of these responsibilities by the State is the reduction of fiscal deficit through expenditure cuts. In effect, the financial costs are transformed into human and social costs.

The 1960s can be considered a benchmark in Caribbean history. It was the period when most Caribbean countries were seeking their political independence from the metropolitan countries. It was also a period when the region witnessed a reduction of mortality in the Caribbean. This was followed by consistently high fertility rates which led to a substantial growth of the population. Caribbean economy was invigorated by a process of import substitution, in which industry and services played an important role. This was characterized by a steady growth of the per capita product. Simultaneously with these changes, far reaching social changes also took place, as evidenced by the strengthening of the middle classes and wage-earners, increases in the level of education and rapid urbanization. The changes in the economic and social structures of the Caribbean were accompanied by a number of cultural contributions such as the small size of families which was facilitated by the implementation of family planning strategies. These processes resulted in a decline in fertility rates which had a deflating effect on the average annual population growth rate which fell from $2.7 \%$ in 1950 and 1960 to $1.8 \%$ during the first half of the 1990s (ECLAC/CDCC 2005).

As the decline in the population growth rate was taking hold, the critical 1980s were ushered into the region. The Caribbean found itself in a serious crisis which jeopardized many economic and social advances that had been achieved during the postwar period. The 1980s' recessive cycle caused serious macroeconomic imbalances and cancelled out some of the progress achieved in the social sphere. Regionally, the impact was felt most in the supply of services such as health, education and the operation of the labour market. Despite the lower population growth rate, the impact of this reduction was offset by the transfer of the previously higher rate, which led to larger cohorts of women of childbearing age. The region was faced with a situation of having to deal with lower fertility rates, which was compounded by a rising birth rate. The demand for social services continued to increase, while the supply was grossly inadequate. At the same time the growing number of young people of working age contrasted with the slowdown in the creation of jobs, leading to significant increases in unemployment and underemployment. The social demographic inertia, which was intertwined with the recessive processes in the economic and social spheres, posed serious challenges to development, and will continue to do so in the future. Hence there is a need to understand the population dynamics that are involved.

\section{Fertility as a Socio-Demographic Variable}

To understand the population dynamics that are involved, the essay will focus on three important socio-demographic issues. The first one is fertility which according to Wikipedia is the actual production of offspring, rather than the physical capability to produce which is termed fecundity. In the Caribbean fertility continues to occur early in life especially among the most vulnerable groups in the population. The situation is compounded with the existence of pronounced gender inequalities, in the form of female heads of household who are required to undertake the responsibility of bringing up 
children. Brown (2002) identified fertility in the Caribbean as following a historical trend of decline towards replacement and below replacement levels and according to Guengant (1990), this is in keeping with the hypothesis that the Caribbean is experiencing a demographic transition governed by the control of mortality in general and infant mortality in particular. Since for much of the $19^{\text {th }}$ century and up to the 1950's, fertility in the Caribbean was high. Given the high levels of mortality that prevailed during this era, fertility was high but its contribution to population growth depended on the levels of mortality and outward migration that prevailed (Brown 2002). Fertility trends have contributed to a change in the age structure of the population; the ageing of the population will lead to an increase both absolute and relative in the population of reproductive age as well as in the population of productive and passive ages. An immediate effect of this process is the marked growth in the number of persons wishing to enter the work force, particularly young people, who are suffering the effects of high unemployment rates. Mortality has been declining at a continuous pace in the region. Along with this change in reproductive behaviour, reductions in mortality were reflected in longer life expectancy at birth, which rose from 52 to 69 years between the early 1960s and the 1980s, and is today, around 70 years. It has been suggested that failure of the Caribbean agricultural agenda coupled with non-industrialization, over urbanization and massive emigration led to the emergence of a mind set that shifted from the view that large family was a good thing. Guengant (1990) has identified the spread of primary education as the main contributor.

According to Brown (2002), there are nonetheless pockets of women within the population that have not followed this trend. These women are usually from disadvantaged social backgrounds, oftentimes the victims of chronic or intergenerational poverty. His findings have shown that they are educated up to primary school level, lack employment skills and face bleak economic prospects. Their high fertility is as much a product as it is a cause of their poverty. In fact, they are socialized into a culture of poverty (Lewis 1969). Brown (2002) continues by stating that the poverty that reduces the capabilities of these women to cope with their social and economic circumstances is itself reinforced by their fertility behavior. Their high fertility is brought about by the fact that they have their children more frequently and start child-bearing at a younger age. Even where national fertility rates are declining, the circumstances of the poor tend to foster attitudes of hopelessness, and fatalism that make them less receptive to the family planning message than the non-poor groups.

Further findings by Brown (2002) have identified a clear relationship between age of first birth and socioeconomic status. The majority of first births occur to women less than 20years of age. In the Caribbean high adolescent fertility is thus a feature of high total fertility. High fertility among adolescents, however, is attributable to the fact that even in countries with a low overall fertility rate, a large proportion of women have their first child during adolescence. At the community level the high fertility patterns is associated with a particular household and demographic structure and with the absence of certain amenities and facilities. These features tend to be associated with a lack of job market and socialization capabilities. This phenomenon is indicative to an understanding of the vulnerability of these women within the social structure of these societies. One can therefore appreciate why HIV/AIDS is endemic in the Caribbean. History, culture, political economy and education are all independent variables that are associated with behavior.

\section{Aging as a Socio-Demographic Variable}

Generally speaking, population structure is the distribution of a country's population by age and sex. These two potential sources of vulnerability impact heavily on youth dependency and elderly dependency. Research in the region has shown that not withstanding declines in mortality and fertility, the dependency ratios are still relatively high. Elderly dependencies are probably the highest they have ever been in the region's history (Brown 2002).

Today the Caribbean like many parts of the world is witnessing an increase in the population among the elderly. The demographic transition and its implications, anticipated an expanded elderly population world wide since the aging of the world's population had been predicted as the most certain reality of the $21^{\text {st }}$ century. The aging of the population in the developed countries is a topic of much current research and discussion. This aging is in large part a function of declining and low fertility levels. The impact of migration on this process is considered relatively less and in many cases minimal. Declining and low levels of mortality play at most a minor role in the aging of the population. In fact it is the aging of the population due to low fertility which is seen as a determinant of the current levels of mortality. One of the outcomes of the declining mortality, fertility and migration of working age persons that the region has witnessed is an increase in 
the relative share of the total population by the older age groups of which it is comprised. Additionally, the elderly population in the Caribbean will also be incremented by the return of migrants, now elderly, who left the region in the beginning in the 1960s (Paul 2001).

Lewis (1995) argued that life expectancy in the Caribbean rose from an average of 50 in the late 40's to and average of 70 for men and 73 for women in most of the English Speaking Caribbean, with the population of those over 65 years rising from around 4 to $10 \%$ over the period 1950-90. Throughout the English Speaking Caribbean, the elderly now represents 10-13 percent, being 10\% in Jamaica, 11\% in Trinidad and Tobago and $13 \%$ in Barbados. In very few countries would we find the elderly population being as low as $7.5 \%$ as we see for Guyana (PAHO 2005).

The population 60 years and over, has now grown so large that unlike in the past, their concerns and those of their families can no longer be ignored. According to Eldermire (2008), not only has the population aged, but the group over 80 years is the fastest growing group. The Pan American Health Organization (PAHO 2005), sighted Barbados as having $10 \%$ of its population 85 years and older. Barbados's low dependency and relatively high proportion of population in the economically active age groups is probably the demographic basis of its high per capita income and economic prosperity (Brown 2002). This unrelenting aging of the region's population brings to the fore a number of risks for the individual, the family, community and the society from the standpoints of health care and social security. Susceptibility to disease increases with age which is accompanied by the demands of an aging population on the health care system. Similarly, as individuals grow older their ability to earn an income diminishes. The United Nations defines older persons as those persons in the population aged 60 years and over. However, distinctions are made between the younger elderly aged 60-74 and the older elderly aged 75 years and older.

Economic development in the region is accompanied by cultural change from traditional to modern. Older individuals now have to live in a world in which people are just beginning to come to grips with the increased number of older persons. Within the Caribbean society, the respectability and reverence that previously was automatic for older persons is no longer the case. Older persons are being robbed, abused, and in other ways violated. Worse still, society had earlier designated a number of negative stereotypes to the elderly and their way of life, which makes life sometimes very frustrating and extremely difficult for older people. This has not changed much despite the growing number of older persons. Therefore, for many older persons especially the less financially able and the more vulnerable, growing older can be especially challenging. It is important to note that at this point the importance of gender. Life expectancy has increased all around, but women have an added 4-5 years over men in all the Caribbean countries. Therefore women make up a significant majority of the 60 year within the population of the Caribbean.

Table 1. Total Population 60 years and over in four Caribbean countries.

\begin{tabular}{lll}
\hline Country & Males & Females \\
\hline Barbados & 17,770 & 24,485 \\
Grenada & 5,770 & 7,373 \\
Guyana & 27,976 & 32,566 \\
Trinidad and Tobago & 64,379 & 76,497 \\
\hline
\end{tabular}

Source: Caribbean Epidemiological Centre (CAREC) 2010.

According to Eldemire-Shearer (1997), in Jamaica the needs of older persons differ according to gender. The same could be said for the needs of older persons throughout the region, where anecdotally men often have social needs and women more financial needs. In the case of Trinidad Rawlins (2008) showed 36\% of the men in receipt of private pensions or government pensions while only $12 \%$ of the women were in receipt of such pensions. This relates to the fact that women of this age group would have spent much less time in full employment, than would their male counterparts.

The writer of this essay seeks to address some of the main concerns associated with the vulnerability of individuals, their families and communities in catering to the needs of older persons and the government ministries and agencies which are charged with the specific responsibility of treating with issues relating to older persons in the society. The vulnerability of individual vary depending on the country in which they live, their level of integration into society, their relationship with children and other family members and their general socio-economic situation. However high on the list of vulnerably for older persons are issues such as: family interaction, intergenerational cooperation, living arrangement, financial security, savings, pension, homelessness and poverty. Other vulnerability issues for the individual would relate to health issues such as ill health, health care cost, long-term hospitalization and the need for reliable family care givers and efficient care givers in the institutional setting. 
The concerns that would engage the minds of familymembers would also vary in relation to the country in which they live, the services which are available to older persons and their socio-economic situation. One way to better understand the importance of family to the elderly is to look at the living arrangements of older persons. A study done by the Pan American Health Organization (PAHO 2005), reported for Barbados that just over one-fifth of elderly Barbadians live alone and that among the elderly with children $23.1 \%$ women and $16.3 \%$ of men lived with at least an offspring.

Comparable to Barbados, Rawlins et al (2008) highlighted that in Trinidad, $16 \%$ of the elderly sampled lived alone. In another study of older women in Trinidad (Rawlins 2009) noted that 18.5\% lived alone and $79 \%$ owned their own home but had relatives living in their home with them. This introduces the issue of the older person with a valued resource. According to Peil (1991), help when given to older persons, was dependent on the resources available to the giver. When the older person owns a home, this has the potential to change the interaction with relatives, in favour of the older person.

In the Trinidad study Rawlins et al (2008) also found that older persons reported loneliness for them was one of the most significant concerns. In that study $33 \%$ of the sample of 845 elderly males and females, reported feelings of loneliness. What was also significant in the study was that although many individuals were lonely, only $16 \%$ lived alone. This high level of 'loneliness' speaks to the need to examine the relationship between older persons and those with whom they live, with a view to improving intergenerational interactions. The majority of elderly persons $(70 \%)$, of those who reported that they were lonely stated that their family and friends were too busy to spend time with them.

\section{Health and the Aged}

The term 'aged' as a socio-demographic variable, is implicated within a context of vulnerability when health and health care issues are focused on the elderly population within the region. In the Caribbean region the leading causes of morbidity, that is, serious illness leading to hospitalization, in several studies in the region are heart diseases, stroke and diabetes (see Table 2). The high rate of chronic conditions draws attention to the reality that in these societies the epidemiological transition has presented a situation in which there is now demonstrated a shift from infectious to chronic diseases as major causes of death.
Table 2. Leading Causes of Mortality (65+ years) CAREC Member Countries (2004).

\begin{tabular}{lll}
\hline Causes of Death & Sample Size & Percentage \\
\hline Ischemic heart disease & 2179 & 14.9 \\
Cerebrovascular disease & 2080 & 14.3 \\
Diabetes & 1724 & 11.8 \\
Hypertensive diseases & 1111 & 7.6 \\
Influenza and Pneumonia & 618 & 4.2 \\
Malignant neoplasms & 571 & 4.0 \\
\hline
\end{tabular}

The aged due to the degenerative physiological activities of the body are more susceptible to chronic diseases since the aging process is tied up within the development process. Prevalence of chronic degenerative diseases has its origins in the environment. The challenge which countries such as the Caribbean now confront is: how will they manage the huge burden of chronic diseases in the growing elderly population and at the same time provide the resources for the continued management of the infectious other conditions which have not been eradicated.

Because older persons are living longer, it means that they have more time/years for complications to set in, with for example, their diabetes, heart disease and hypertension. These conditions often lead to their disability, resulting in the need for more intensive interaction with the health care sources, expensive treatments and hospitalization. The ready availability of good quality, affordable health care in these circumstances is of critical importance. However, changes in the global economy that began in the last three decades of the twentieth century have been associated with economic crisis that threatened the capability of the Caribbean state in terms of its ability to subsidize social services for the population. Private sector health insurance has become the alternative to state subsidy. The question is: who are the ones that can afford this type of insurance? Obviously, it would be the well- to- do who are the once high up in the socio-economic ladder and who make up a very small percentage of the population.

\section{Economic Issues and the Aged}

Financing one's self in old age is often one of the greatest concerns of the older person. Theodore, (2004) argued that even persons who have been most prudent in their 30's and 40's find that "the previously made provisions will be inadequate". Inflation over the years renders savings of little value to large numbers in their old age. In Trinidad and Tobago, Barbados and Jamaica, the elderly are financed by institutions such as national insurance schemes, private retirement schemes, government 
retirement schemes, old age pensions and public welfare. Cloos (2008) extended the argument by adding church and family as economic providers. It can therefore be said that older persons who have made careful plans for the future will find that they face economic challenges, more so if ill health befalls them and they need to be treated within private health care facilities; where in 2009 rates were as high as TT \$1800 (us 300) per night. Unfortunately, there are older persons who because of life experiences, family problems, or other reasons, made no plans for their general care and health care in their old age. Some older persons will find themselves homeless because of these and other family reasons.

Despite all efforts, there is yet a great deal to be done. The majority of elderly persons in the region comprised of one of the most vulnerable groups. There are still homeless elderly persons and elders who are underserved in terms of health care, housing and pension benefits. As the elderly population increase in the region, so also the dependency ratio will continue to change. Research has shown an increasing number of older persons for each "working" person in the population. However given the global economic recession and its impact in the region, the individuals on whose shoulders the elderly are accustomed leaning upon will not be able to provide as generously as they might have done previously.

The region governments are trying with the necessary support systems ifor elderly persons such as social security. However, most of these systems were built on premise that there will always be significantly fewer older persons than younger or middle-aged individuals living at one time. Because of declining death rates, therefore, these systems are beginning to feel a strain that will only increase overtime. Additionally, the older-person-support ratio is falling in both more and less developed regions, which could further lessen the ability of societies and governments to care for their aging populations.

These socio-demographic trends create unique challenges for the region, particularly for the governments of these societies. Elderly individuals are often subject to discrimination and abuse because they are perceived as easily taken advantaged of. There is a prevalent belief among many that elderly persons are worthless in today's fast-paced, globalized and increasingly industrialized world. Obviously, with the number of elderly people on the earth at any one time rising rapidly, there is an increased urgency to address the vulnerability and risks of this group.

\section{Migration}

Migration, as a socio-demographic issue is all tied up in the history of the region. Escape or the contemplation of escape probably preoccupied the thoughts of Caribbean slaves. This seems to be why birds and boats, obvious symbols of migration, were important among enslaved Afro-Caribbean peoples (Patterson 1978). Thomas-Hope (1986) argued that migration has become deeply embedded in the psyche of Caribbean peoples over the past century and a half. It has evolved as the main avenue for upward mobility through the accumulation of capital, both for financial and social needs. Thus the propensity for migration is high and there is a general responsiveness to the opportunities for moving whenever they occur. At times these opportunities have come from within the region itself or the wider circum-Caribbean region, as in the late nineteenth and early twentieth centuries; in more recent times from North America and Europe (Thomas-Hope 1986).

Caribbean migration includes a wide variety of movements which can be classified on the basis of the stated purpose of the movement, whether work, education, or as an accompanying person; or length of stay at the destination, whether permanent or temporary. Any of these migrant types may have some significant impact on the population dynamics within the region. For many people in the Caribbean, the search for a better life has quite often begun within the region. This has become evident through the fact that the absolute number of foreign-born nationals originating in the Caribbean present in another country in the sub-region has steadily increased over the last two decades. According to the United Nations (2002) stock data, there is an increase in the number of migrants in the Caribbean. While the absolute migrant stock is comparatively small in the Caribbean, the migrant stock as percentage of the population is considerably high. Research has shown that on an average, about $3 \%$ of the Caribbean population can considered migrants. This, however, varies considerably from country to country, with the lowest percentage found in Jamaica, Guyana, Cuba, and the Dominican Republic and the highest proportions reported for the British Virgin Islands, the Cayman Islands, Anguilla, the Netherlands Antilles, Aruba and the United States Virgin Islands. The majority of migrants originate in just a few countries, mainly in the smaller member States of the Organization of Eastern Caribbean States. The push factors are the deteriorating economic and social conditions, high unemployment particularly for younger people and little hope for improvement in 
the foreseeable future. One can therefore understand the desperation which is associated with the survival instinct.

According to research done by (ECLAC/CDCC 1998) immigration has tremendous impacts on the life of the national population of the receiving country. Another study (Oakes 1992) on the situation of migrant workers in the British Virgin Islands portrays the implications that the work-permit has on the migrant and his/her legal status in that country. With the exception of a few naturalized citizens, most immigrants remain temporary workers for their entire stay and this hold even for those 'temporary' migrants, who have lived in the host country over extended periods of time. Being 'temporary' implies being subject to deportation at any given time and have no access to basic health-care services and education for children.

The population dynamics of migration in the Caribbean is very complex. The writer has tried to address the interregional migration issue but what about the extra-regional migration issues and their impact on the region? Caribbean skilled professionals are on the move worldwide. Countries like Jamaica, Cuba and Trinidad and Tobago, are strong exporters of qualified labour, particularly teachers, nurses, and other health professionals. Family ties, geographic proximity and the use of the same language make the United States and Canada and, to a lesser extent, the United Kingdom a preferred destination for migrants from the Caribbean. Increasing job opportunities in certain sectors of the labour market along with the hope of a prosperous life make moving north an attractive option for many Caribbean nationals.

Looking at the phenomenon from an economic point of view, some governments in the region will favor the exodus of their skilled in exchange for desired remittances to boost their economies since they suffer tremendous constraints in their capacities to provide equal, qualitative and affordable social services to their populations. Worse, the continued depletion of professionals deprives the region of its desperately needed qualified staff whose education and training were often a considerable expense to taxpayers. Since qualified professionals play a critical role in sustainable development, this continuous loss threatens to paralyze progress underway in the economic and social sectors in the region.

The impact of migration in the Caribbean cannot dismiss the implications it has for gender dynamics. It is therefore, reasonable to expect the relatively low sex ratio evident in extra-regional migration as a result of the Developed Countries profiles of skill shortages and consequent vacancies in need of filling by labour migrants. For example, there is growing recognition in the US of an acute shortage of nurses in schools; the current census indicates a nurse-tostudent ratio of 1:1, 466 and this is barely half of the ratio recommended by the federal government. School districts are generally under tight budgetary constraints, with the result in 2004, that the median pay for school nurses was some US $\$ 20,000$ per year less than the median pay in hospitals and clinics (Horovitz 2005). Thus while there is a general shortage of nurses in the US health sector, their scarcity is even more dramatic in the educational sector. Given the apparent comparative advantage held by nurses from the English-speaking Caribbean, there is reason to expect buoyant flows of female labour migrants in the future.

\section{Conclusion}

In this essay the writer depended heavily on the analysis of secondary data to explain the role of socio-demographic factors in predisposing Caribbean society to vulnerability. It can be suggested that vulnerability is a function of the region's stock of capabilities that enables it to respond to threats posed by different socio-demographic risks. Fertility which is associated with the reproductive age in the population, has been threatening the region in the form of lags or delays. The literature has shown this phenomenon as enduring among women in the disadvantaged socioeconomic groups across the region. In these groups, teenage pregnancy and multigravida are the order of the day. If left unabated, one can imagine the kind of threat this phenomenon can pose to the region in terms of the inability of these young women to properly prepare themselves and their families for full and active participation in the economy and their society. The social disorganization of the communities in which these young women reside has created 'an attitude of fatalism and a sense of powerlessness which seem to shield these young women from the influence of the conventional family planning strategies (Brown 2002). There is need to improve the education system in the region so that teaching strategies must be applicable equitably to all socio-economic groups.

This essay is written in full recognition that not all older persons are sick or dependent. Whatever the condition of our older population, the region's people need to be brought up to speed with regard to all the issues that are relevant to the lives of older persons. Already throughout the region there are educational training initiatives that are seeking to inform and prepare various segments of the population to be able to engage with older persons, their relatives and their 
concerns. Medical doctors in the region are now being trained in social gerontology which will assist them in understanding some of the concerns of older persons. Despite all the efforts, there is yet a great deal to be done. There are still homeless elderly persons.

The writer believes that families and older persons should become very creative over the next two decades to ensure their livelihood and social and economic comfort. One way will be that older persons should not feel the need to rush out of the workforce at age 60 or 65 years, but should consider, along with their employers, how they could continue contributing to society, even if part-time by remaining in the workforce. This would bestow economic, social, and health benefits for the older persons, and many long-term benefits for society.

Migration researchers have identified that the root causes of Caribbean migrations are intertwined with the developed world, both now and in the past. Since the 1960s the accelerating magnitude and breath of international capital investment, mainly from the United States has helped create a heightened international labour demand and the rise of "global cities" that have attracted, among others, tens of thousands of Caribbean peoples. Investment capital devoted to modernizing Third World countries often disrupts traditional agricultural systems, uprooting people and catapulting them into the wage labour market such as occurred in the Greater Antilles in the early $20^{\text {th }}$ century. Today, these labour movements routinely cross international boundaries, movements facilitated by political decisions such as the relaxation of immigration restrictions (Sassen 1988).

Finally, we have seen where for many decades, capitalist investment strategies have been creating local dislocations and incongruities in the Caribbean. These conditions when combined with the region fragmented insularity have helped to produce migration. These incongruities may be said to have begun with the introduced overpopulation that was slavery, and they have created ecological conditions with which Caribbean peoples have had to cope ever since. They also help to explain why human migration has been compelling livelihood strategy in the Caribbean region ever since its people have been free to leave (Richardson 1992).

\section{References}

Brown, D. (2002). Socio-demographic vulnerability in the Caribbean": An examination of the social and demographic impediments to equitable development with participatory citizenship in the Caribbean at the dawn of the twenty-first century, (LC/L, 1704-P).

Cloos, P. (2008). The Caribbean aging study: focus group discussions, 2007-2008". Paper presented at the CHRC sponsored Workshop in April 2008 at the Economic Commission on Latin America and the Caribbean (ECLAC), Trinidad.

Economic Commission for Latin America and the Caribean/Caribbean Development and Cooperation Committee (ECLAC/CDCC). (1998). A study of return migration to the organization of Eastern Caribbean States Territories and the British Virgin Islands in the Closing years of the $20^{\text {th }}$ Century, Port of Spain, Sub-regional Headquarters for the Caribbean.

Eldemire, D. (1993). An epidemiological survey of the elderly in Jamaica, PhD Thesis, University of the West Indies.

Eldemire Shearer, D. ( 1997). The Jamaican elderly: A socioeconomic perspective and Policy Implications, Social and Economic Studies 46 (1), 79-93.

Guengant, J. (1990). Fertility transition in Latin America: An attempt at interpretation, Presented at the Seminar on Fertility Transition in Latin America, Buenos Aires.

Horowitz, B. (2005). Nurse shortage puts school kids at risk. USA Today.

Lewis, M. (1995). The Caribbean health situation, The Caribbean Epidemiological Centre (CAREC), Trinidad.

Mintz, S. (1974). The Caribbean region, Daedalus, 103, (2), 45-71.

Oakes, B. (1992). Workers in the British Virgin Islands: The complexities of residence and migration in: Social and Economic Studies 41 (1), 67-87.

Pan American Health Organization (PAHO). (2008). Health , welfare and aging in Bridgetown, Barbados, SABE 2000. PAHO Technical Paper No. 611. Pan American Health Organization: Washington DC.

Patterson, O. (1978). Migration in Caribbean societies: Socioeconomic and symbolic resource. In Human migration: Patterns and policies, eds. W.H. McNeil and R. S. Adams. Bloomington: Indiana University press, 106-45.

Paul, C. (2001). The life of the institutionalized persons in Trinidad and Tobago, Bridgetown, Faculty of Humanities, University of the West Indies.

Rawlins, j., Simeon, D. T., Ramdath, D.D., \& Chadee, D.D. (2008). The elderly in Trinidad: Health social and economic status and issues of Loneliness. West Indian Medical Journal 57 (6), 589-595.

Sassen, S.(1988). The mobility of labour and capital. Cambrideg: Cambridge University Press.

Richardson, B. C. (1992). The Caribbean in the wider world, 19421992: a regional geography. Cambridge University Press.

Theodore, C. (2004). Financing the needs of the elderly. in Joan Rawlins (ed), Aging: discussing the issues in Trinidad. The University y of the West Indies, School of Continuing Studies Press, Trinidad.

Thomas-Hope, E. (1986). Transients and Settlers: Varieties of Caribbean Migrants and the socio-economic implications of their return, International Migration 24, 559-570. 